\title{
COVID-19 and its impacts: The situation in Niger republic
}

\author{
Emmanuella Nzeribe, PharmD ${ }^{\text {a, }}$, Udofa Edidiong Michael ${ }^{\mathrm{b}}$, Shuaibu Saidu Musa ${ }^{\mathrm{c}}$, \\ Mirindi Batumike Marc ${ }^{\mathrm{d}}$, Success David ${ }^{\mathrm{e}}$, Esther Edet Bassey ${ }^{\mathrm{f}}$, Mohammad Yasir Essar ${ }^{\mathrm{g}, \mathrm{h}}$, \\ Yusuff Adebayo Adebisi ${ }^{i}$, Don Eliseo Lucero-Prisno III $^{j}$
}

${ }^{\text {a }}$ Faculty of Pharmacy and Pharmaceutical Sciences, Kwame Nkrumah University of Science and Technology, Kumasi, Ghana

${ }^{\mathrm{b}}$ College of Health and Life Sciences, Aston University, Birmingham, United Kingdom

c Department of Nursing Sciences, Ahmadu Bello University, Zaria, Nigeria

${ }^{\mathrm{d}}$ Global Health Focus, University of Goma, Congo

e Department of Pharmacy, University of Nigeria, Nsukka, Enugu, Nigeria

${ }^{\mathrm{f}}$ Faculty of Basic Medical Sciences, University of Uyo, Nigeria

${ }^{\mathrm{g}}$ Faculty of Dentistry, Kabul University of Medical Sciences, Kabul, Afghanistan

${ }^{\mathrm{h}}$ Medical Research Center, Kateb University, Kabul, Afghanistan

${ }^{\mathrm{i}}$ Faculty of Pharmacy, University of Ibadan, Ibadan, Nigeria

${ }^{\mathrm{j}}$ Department of Global Health and Development, London School of Hygiene and Tropical Medicine, UK

\section{A R T I C L E I N F O}

\section{Keywords}

COVID 19

Niger

Public health emergency

\begin{abstract}
A B S T R A C T
COVID-19 being a public health emergency of international concern has emerged in most African countries including Niger. Niger, a landlocked country, is tasked with controlling the pandemic. However, of the big challenges the country faced is the fragility of healthcare system which posed limitations to the fight against the virus. The virus overwhelmed the fragile healthcare system which led to inaccessibility of quality healthcare to the citizens coupled with issues of flooding and economic recession that happened during the pandemic. The healthcare sectored has further been crippled by exposure and infection of the already insufficient healthcare workers. In addition to this, there was the burden of NTDs and other communicable and non-communicable diseases that subverted the country in the depths of difficulties. As per the predictions of World Bank, the poverty curve is likely to escalate due to the outrageous impacts of COVID-19. Adding on to this, the occurrence of natural disasters such as flooding has further stretched the country. It's no coincidence that the country would confront plethora of challenges amidst the second wave. Therefore, timely decision and necessary interventions are needed to strengthen the country's fight against the pandemic. However, this is only feasible when Nigerien government, international allies and other wealthy nations work closely to ensure that the challenges faced by the healthcare system are tackled.
\end{abstract}

\section{Introduction}

Niger is a landlocked Sahelian country covering $1,267,000 \mathrm{~km}^{2}$ with a projection of 30 million population by 2030 confirmed its first case in Niamey, the capital city of Niger on March $19,2020 .^{1}$ Niger being the largest country in West Africa is one of the least developed countries of the world and is also recognized as one of the poorest countries. ${ }^{2}$ Prior to the pandemic, the country has been known to be a hub for some of the tropical diseases such as malaria. Malaria has remained one of the leading causes of morbidity and mortality especially in Children below 5 years and pregnant women of which the progress being made by the government has been brought to a halt and affected the National masterplan target for 2020. Furthermore, NTDs were largely left out of the COVID-19 response at local, national, and regional levels. ${ }^{3}$ The COVID-19 pandemic which was declared a Public Health Emergency of International Concern by WHO on January 30, 2020 has globally raised concerns, afflicting various countries in Africa. Meanwhile as of March 2nd, 2021, Niger recorded 4740 cases, 172 deaths and 4250 recoveries according to worldometers. ${ }^{4}$ However, the government has been thrown into action to combat this pandemic via creating some policies and training. Since the emergence of the pandemic in Niger, about 910 healthcare workers and 250 hygiene technicians have been trained on

\footnotetext{
* Corresponding author.

E-mail address: nzeribeella@gmail.com (E. Nzeribe).
} 
Infection Prevention and Control (IPC), 48 lab technicians and 100 biosafety laboratory technicians have been trained on use of GeneXpert and national guidelines and protocols have been established for psychosocial care. ${ }^{5}$ The question remains: Are these enough? Aside from this, the healthcare system faced enormous shortcomings in terms of healthcare facilities supplement to the citizens, and workforce which has further attenuated the country's response to COVID-19. Following the pandemic and the implementation of restrict measures, the economic status of many people severely flattened which has also posed an aggravating burden on country. ${ }^{5}$ Therefore, in this commentary we aim to discuss the current COVID19 challenges faced by the Republic of Niger and what can be done to mitigate the impacts.

\section{Commentary}

The pandemic has tremendously affected the life of the Nigeriens as it has brought the economic activities to a halt due to the restrictions on movements and other preventive measures imposed by the Nigerien government. The country among other African countries is also known to be highly endemic with malaria as well as other tropical diseases which became neglected as the focus became solely on curtailing the virus. ${ }^{3,6}$ Niger currently runs a risk of recession due to the slow pace of economic activities further increasing the poverty rate: currently close to 270,000 Nigeriens have been pushed into poverty due to the pandemic. ${ }^{7}$ This has impacted different sectors of the nation negatively, particularly the health and education sector.

Niger has a poor healthcare system negatively impacted by inadequate funding, inadequate training and inadequate education amidst other issues. Prior to the pandemic, Niger had a poor healthcare coverage with insufficient numbers of qualified healthcare worker. This in addition the lack of medicines negatively impacts the provision of health care. ${ }^{8}$ With the current pandemic and the government imposed preventive measures, the healthcare system is much overwhelmed. Already, as early as April 2020 (barely a month after report of the first case) Niger reported new polio outbreaks due to vaccine deprivation. ${ }^{9}$ This highlights another lurking health issue for the nation having just tackled a 24-month outbreak in December 2, 019. ${ }^{9}$

Currently, not enough Infection Prevention and Control (IPC) measures exist in healthcare facilities to manage COVID-19 in the country. There is an obvious lack of patient triage system, an absence of isolation zones in health facilities with an average performance in use of personal protective equipment. There is also the problem of poor staff training and limited measures to prevent exposure of healthcare workers in integrated health centers and private health facilities. ${ }^{10}$ With $16.6 \%$ of total cases in Niger being healthcare workers this further impacts the healthcare negatively as the workforce in tackling the pandemic and other health issues is greatly reduced, ${ }^{5}$ the care of these exposed workers are not clearly defined and in some cases not ensured. ${ }^{10}$ There also lies the problem of incapacitation of already limited hospitals due to hospitalization of large number of COVID-19 patients, famine and malnutrition due to reduced farming activities and general productivity, and problem of continued insecurity in the Southeast and Southwest amidst the pandemic hindering access to healthcare facilities which all go on to distress the poor healthcare system of Niger. ${ }^{11,12}$ Hence the need for an action plan by the Government in lieu of these challenges to improve prognosis and develop the country.

The impact of COVID-19 was seen on the educational sector where a UNESCO report had it that 1.2 million children and young people were out of school as a result of the restrictive COVID-19 measures thus, bringing the total number of those not getting education to 3.8 million. ${ }^{13}$ The Report further adds that even after schools are reopened and the COVID-19 lockdown measures are lifted, "children in Niger run the highest risk in the world of not returning to school. ${ }^{4}$ The advancing insecurity issue even during the pandemic further incapacitated children's education in some communities. It is worth to note that there were no arrangements for homeschooling or continuing education by the government during the period. ${ }^{13}$ The economic outlook for Niger is further deemed by this. Many children have been reported to have dropped out to assist the financial state of the family, with female children at risk of being given off in child marriage.

The pandemic also disrupted the lives and livelihoods of Nigeriens. This invariably insinuates a strong negative effect of the COVID-19 pandemic on the industrial sector and other economic activities in Niger ${ }^{7}$ Seeing the rapid population growth rate in Niger which is majorly due to the high fertility rate; there is a high chance of this restraining economic development leading to low human development indicators. ${ }^{14}$ Research has shown that there are generally about 750,000 children in a year which usually places more demands on investments into the healthcare and the educational sector and no doubt that for close to 10 years, Niger has ranked close to last in the United Nations Human Development Index.

Citizens of Niger republic have been put in difficult situations due to the impact of the pandemic and this calls for concern about their psychological health. Amnesty International reported that journalists have been arrested over reporting about the pandemic. ${ }^{4}$ In light of the COVID-19 incidence, the pandemic has caused severe distress on the psychology and social life of the people cutting across the globe. ${ }^{6}$ Psychological impacts such as depression, anxiety and mass hysteria has made it hard for the Nigerians to cope in the midst of the pandemic. Humanitarian actors play major role in strengthening psychosocial support but this has been threatened due to restriction of humanitarian movement and access to affected people. ${ }^{8}$ However, in May 2020 health situations were stabilized and restrictions lifted so as to ease the mental and economic hardships of the people. This relief may be short-lived with the recent surge in COVID-19 cases in the world especially the massive second wave in Niger's southern border: Nigeria and recent reopening of this border for trade purposes. ${ }^{15}$

With the completion of clinical trials for COVID-19 vaccines and the roll out of vaccination programs in developed and rich countries, what is the hope for Niger Republic? With the recent acquisition of 270 million vaccines for Africa by the African union in addition to the 600 million vaccines dose from the COVAX effort for lower-income countries. ${ }^{16}$ However, with a population of 1.3 billion people in Africa and each individual requiring two doses for immunity, it is obvious that there will be a vaccine shortage. Niger being a least developed country and not a key player in Africa further darkens the prospects as there are speculations that poorer countries may wait longer periods to be inoculated than richer countries.

\section{Conclusion}

The Nigeriens were obviously not exempted from the impact of COVID-19. The Niger healthcare system has a lot of formidable challenges. No doubt that these challenges do deter the efforts being put in place to improve the healthcare system meanwhile other sectors are suffering loss. The government will be required to strike a balance between shifting the limited and available resources to address the public health emergencies as well as the existing challenges in both the healthcare system and other sectors of the country.

\section{References}

1 Luc R, Vinayaya S. Can Niger escape the demographic trap?. Available at https://n logd.worldbank.org/africacan/can-niger-escape-demographic-trap; 2020. Accessed March 2, 2021.

2 Tchole AIM, Li Z-W, Wei J-T, et al. Epidemic and control of COVID-19 in Niger: quantitative analyses in a least developed country. Journal of global health. 2020;10, 020513-020513.

3 Doudou MH, Mahamadou A, Ouba I, et al. A refined estimate of the malaria burden in Niger. Malar J. 2012;11:89. https://doi.org/10.1186/1475-2875-11-89.

4 Niger Population. Available at https://www.worldometers.info/coronavirus/coun try/niger; 2021. Accessed March 2, 2021.

5 World Health Organization Regional Office: Africa. COVID-19 external situation report. Apps.who.int.; 2021. Available at https://apps.who.int/iris/bitstream/h 
andle/10665/334003/SITREP_COVID19_WHOAFRO_20200826-eng.pdf (Accessed: 2nd March, 2021).

6 Ikwu NA, Igwe DC, Nwawundu SE, Adebayo SA. Impact of covid-19 pandemic on africa's healthcare system and psychosocial life. European Journal of Medicine and Natural Science. 2020;4(2).

7 To better address the COVID-19 crisis, Niger should focus on health measures and on protecting jobs and livelihoods [internet]. Available at. World Bank; 2020. https ://www.worldbank.org/en/news/press-release/2020/10/28/to-better-address-the -covid-19-crisis-niger-should-focus-on-health-measures-and-on-protecting-jobs -and-livelihoods, 2020. Accessed December 25, 2020.

8 Ocha. Niger Humanitarian needs are exacerbated [Online]. Available at https://rep orts.unocha.org/en/country/niger/card/2LAGoFyXgL/; 2020. Accessed March 2, 2020.

9 EnerCagriDinleyici Ray Borrow, Marco Aurélio Palazzi Safadi, Munoz Pierre van Damme \& Flor M. Vaccines and routine immunization strategies during the COVID19 pandemic. Hum Vaccines Immunother. 2020. https://doi.org/10.1080/ 21645515.2020.1804776.

10 Abdoulaye Mariama Baissa SH, Ali Mahamane, Arlette Leufak Mouako, BlanchePhilomene Melanga Anya CSW. The fight against COVID-19 in Niger: evaluation of infection prevention and control in health facilities in the urban community of Niamey. The Pan African Medical Journal. 2020;31.
11 Okereke M, Ukor NA, Adebisi YA, et al. Impact of COVID-19 on access to healthcare in low- and middle-income countries: current evidence and future recommendations. The International journal of health planning and management, 10.1002/hpm.3067. Advance online publication. 2020. HYPERLINK 10.1002/hpm.3067.

12 Working with communities during a pandemic in Niger. At https://www.msf.org/w orking-communities-niger-during-covid-19-pandemic; 2020. Accessed March 2, 2021.

13 Niger - 1.2 million children and young people were out of school because of COVID19 | Save the Children International. Save the Children International; 2020. Available from https://www.savethechildren.net/news/niger-\%E2\%80\%93-12-million-chil dren-and-youngpeople-were-out-school-because-covid-19. Accessed December 23, 2020.

14 African Union Report. Impact of the coronavirus on the african economy. Available at: https://au.int/sites/default/files/documents/38326-doc-covid19_impact_on_afric an_economy.pdf; 2020, 29-12.

15 CGTN. December 16. Nigeria lifts closure of borders with Benin and Niger [Online]. Available https://africa.cgtn.com/2020/12/16/nigeria-lifts-closure-of-borders-withbenin-and-niger/; 2020. Accessed March 2, 2020.

16 BBC. Africa secures $270 \mathrm{~m}$ Covid-19 vaccine doses [Online]. Available at https://www.bbc.co.uk/news/world-africa-55656578; 2020. Accessed March 2, 2020 . 